\title{
Molecular identification of Trichinella isolates from wildlife animals of the Russian Arctic territories
}

\author{
K. GOŹDZIK ${ }^{1 *}$, I. M. ODOEVSKAYA², S. O. MOVSESYAN ${ }^{3}$, W. CABAJ ${ }^{1}$
}

\begin{abstract}
'Witold Stefanski Institute of Parasitology, Polish Academy of Sciences, Twarda 51/55, 00-818 Warsaw, Poland, *E-mail: kasiagoz@twarda.pan.pl; ${ }^{2}$.I. Skryabin's All Russian Institute of Fundamental and Applied Parasitology of Animals and Plants, Agricultural Academy of Sciences, Cheremushkinskaya St. 28, 117218 Moscow, Russia; ${ }^{3}$ Center of Parasitology, A.N. Severtsov Institute of Ecology and Evolution, Russian Academy of Sciences, 33 Leninskij prosp., 119071 Moscow, Russia
\end{abstract}

\section{Article info}

Received September 29, 2016 Accepted December 13, 2016

\section{Summary}

The parasitic nematodes of genus Trichinella are infective to a wide range of hosts, including humans, and have global distribution from tropic to arctic areas. Muscle samples from animals, collected in two areas of the Russian Federation, Chukotka Peninsula and Arkhangelsk Oblast, were tested for the presence of Trichinella spp. larvae. Trichinella spp. larvae were recovered from tissues of eleven wild and domestic animals: 1 polar bear, 1 wolverine, 3 arctic foxes, 1 ringed seal, 1 brown bear, 1 cat, 1 sled dog, 1 domestic pig and 1 northern sea lion.

Two molecular methods, multiplex PCR and inter-simple sequence repeat polymerase chain reaction (ISSR PCR), were utilized for species identification. T. nativa was identified in the majority of tested animals and mixed infections with two Trichinella species were detected in four animals. $T$. spiralis/T. pseudospiralis mixed infection was found in a domestic pig and T. spiralis/T. nativa in two arctic foxes and a northern sea lion.

Here, for the first time, Trichinella spp. infection in a northern sea lion and the northern sea lion as a new host for $T$. spiralis and T. nativa is reported. Discovery of Trichinella spp. infection in a new host, such as a northern sea lion, which is an opportunistic marine predator, mainly feeding on fish, indicates environmental contamination. Leaving of carcasses or waste from animals and improper management of livestock operations is important for spreading Trichinella spp. infection in free living animals. Therefore, further extensive epidemiological and environmental research and molecular studies are needed to investigate the local fauna.

Keywords: Trichinella; new host; isolates; wildlife animals; Russia

\section{Introduction}

Parasitic nematodes of the genus Trichinella have a wide host range, including the man, and geographical distribution from tropic to arctic areas. In nature Trichinella parasites are maintained in sylvatic and in domestic life cycles. The sylvatic cycle occurs mainly in carnivorous animals with cannibalistic or scavenger behavior and the domestic cycle mainly through domestic pigs and synanthropic rats (Pozio, 2000).
Currently, nine species (Trichinella spiralis T1, Trichinella nativa T2, Trichinella britovi T3, Trichinella pseudospiralis T4, Trichinella murrelli T5, Trichinella nelsoni T7, Trichinella papuae T10, Trichinella zimbabwensis T11 and Trichinella patagonensis T12) and three genotypes (T6, T8 and T9) within two clades (encapsulated and non-encapsulated) are recognized. From these, four species of Trichinella, T. spiralis, T. nativa, T. britovi and T. pseudospiralis, are known to exist in animals in Russia (Pozio, 2009; Gottstein et al., 2009; Krivokapich et al., 2012).

\footnotetext{
* - corresponding author
} 
T. spiralis exhibits a wide global distribution in temperate and equatorial climatic zones and is most adapted to the domestic pigs and wild boars but can also infect synanthropic animals such as rats, horses, stray cats, and dogs. It is also the most important etiological agent to cause disease in humans. Three other species T. britovi, T. nativa and T. pseudospiralis are widely distributed in sylvatic animals. The main reservoirs for $T$. britovi are foxes and raccoon dogs, and also the other carnivores such as wolf, bear and mustelids. T. nativa was primarily found in arctic and subarctic carnivores. Polar bears, brown bears, wolves, foxes, raccoon dogs and mustelids serve as reservoirs. This species is rarely found in naturally infected wild boars, domestic pigs and other livestock. $T$. pseudospiralis is a cosmopolitan species, has the largest spectrum of the hosts and can infect both mammals and birds (Kapel, 2000; Pozio, 2009).

The identification of Trichinella larvae in samples from wildlife animals is required to monitor the prevalence of Trichinella infection among the wildlife reservoir and to predict the risk of introduction into domestic animals.

Today, for identification of Trichinella larvae at the species level molecular techniques, especially polymerase chain reaction based tests, are widely utilized. One of these tests routinely used in laboratories is a multiplex PCR developed by Zarlenga et al. (1999). Another technique for differentiation of Trichinella larvae is an inter-simple sequence repeat polymerase chain reaction (ISSRPCR) described by Fonseca-Salamanca et al. (2006). In both methods seven Trichinella species/genotypes (T1, T2, T3, T4, T5, T6, T7) can be identified.

In the international literature information on Trichinella infections on the Russian territory is still scarce. In the majority of the available publications, Trichinella infections were confirmed by microscopic examinations of tissues obtained from domestic and wild animals or by detection of antibodies in the sera of tested animals and/or humans (Bukina et al., 2013; Bukina, 2014; Odoevskaya and Spiridonov, 2014; Odoevskaya et al., 2015). However, morphological methods, as well as serological tests are insufficient to distinguish the species.

To improve the knowledge about the occurrence of these parasites in domestic and wildlife animals and for epidemiological studies, all Trichinella isolates should be identified at the species level (Gottstein et al., 2009).

In the presented study we focused on molecular identification of

Table 1. Identification of Trichinella larvae isolated from wild-life and domestic animals in the Russian Arctic territories

\begin{tabular}{|c|c|c|c|c|}
\hline No. of sample & Animal species & Locality & $\begin{array}{l}\text { Molecular identification } \\
\text { using multiplex PCR }\end{array}$ & $\begin{array}{c}\text { Molecular identification } \\
\text { using ISSR PCR }\end{array}$ \\
\hline 1 & $\begin{array}{c}\text { polar bear } \\
\text { (Ursus maritimus) }\end{array}$ & $\begin{array}{c}\text { Chukotka Peninsula } \\
\text { Jakucja }\end{array}$ & $\mathrm{T} 2$ & $\mathrm{~T} 2$ \\
\hline 2 & $\begin{array}{l}\text { wolverine } \\
\text { (Gulo gulo) }\end{array}$ & $\begin{array}{c}\text { Chukotka Peninsula } \\
\text { Jakucja }\end{array}$ & $\mathrm{T} 2$ & $\mathrm{~T} 2$ \\
\hline 3 & $\begin{array}{c}\text { arctic fox } \\
\text { (Vulpes lagopus) }\end{array}$ & Chukotka Peninsula & $\mathrm{T} 1 / \mathrm{T} 2$ & nd \\
\hline 4 & $\begin{array}{c}\text { arctic fox } \\
\text { (Vulpes lagopus) }\end{array}$ & Chukotka Peninsula & $\mathrm{T} 2$ & $\mathrm{~T} 2$ \\
\hline 5 & $\begin{array}{l}\text { farmed arctic fox } \\
\text { (Vulpes lagopus) }\end{array}$ & Chukotka Peninsula & nd & $\mathrm{T} 1 / \mathrm{T} 2$ \\
\hline 6 & $\begin{array}{l}\text { wild domestic cat } \\
\text { (Felis catus) }\end{array}$ & Chukotka Peninsula & nd & $\mathrm{T} 1$ \\
\hline 7 & $\begin{array}{l}\text { ringed seal } \\
\text { (Pusa hispida) }\end{array}$ & Chukotka Peninsula & $\mathrm{nd}$ & T4 \\
\hline 8 & $\begin{array}{l}\text { northern sea lion } \\
\text { (Eumetopias jubatus) }\end{array}$ & Chukotka Peninsula & nd & $\mathrm{T} 1 / \mathrm{T} 2$ \\
\hline 9 & $\begin{array}{l}\text { brown bear } \\
\text { (Ursus arctos) }\end{array}$ & Arkhangelsk Oblat & $\mathrm{T} 2$ & $\mathrm{~T} 2$ \\
\hline 10 & $\begin{array}{c}\text { domestic pig } \\
\text { (Sus scrofa domesticus) }\end{array}$ & $\begin{array}{c}\text { Chukotka Peninsula } \\
\text { Kamczatka }\end{array}$ & $\mathrm{T} 1 / \mathrm{T} 4$ & $\mathrm{~T} 4$ \\
\hline 11 & $\begin{array}{c}\text { sled dog } \\
\text { (Canis domesticus) }\end{array}$ & Chukotka Peninsula & $\mathrm{T} 2$ & T2 \\
\hline
\end{tabular}

T1 - T. spiralis; T2 - T. nativa; T3 - T. britovi; T4 - T. pseudospiralis; nd - not determined 
Trichinella larvae recovered from wildlife and domestic animals collected from two regions of the Russian Federation, Chukotka Peninsula and Arkhangelsk Oblast.

\section{Materials and Methods}

Muscle samples were collected in years 2010 and 2011, during the examinations of domestic, synanthropic, and wild animals, by local investigations. Trichinella larvae were recovered from animals' muscles by enzymatic digestion method according to standard protocol (European Commission, 2005) and preserved in ethanol while shipped for molecular identification to the Witold Stefański Institute of Parasitology, Polish Academy of Sciences, Warsaw, Poland.

Trichinella isolates were obtained from 11 naturally infected wild and domestic animals from two areas in the Russian Federation. Ten isolates were obtained from animals captured in the northeastern region of Russia, Chukotka Peninsula in the Far Eastern Federal District $\left(66^{\circ} \mathrm{N} 172^{\circ} \mathrm{W}\right)$, and one isolate, was obtained from Arkhangelsk Oblast in the Northwestern Federal District $\left(63^{\circ} \mathrm{N} 43^{\circ} \mathrm{E}\right)$. Trichinella larvae were recovered from one polar bear (Ursus maritimus); one wolverine, (Gulo gulo), two wild arctic foxes (Vulpes lagopus) and one farmed fox, one domestic cat (Felis catus), one ringed seal (Pusa hispida), one brown bear (Ursus arctos), one sled dog (Canis domesticus), one domestic pig (Sus scrofa domesticus) and one northern sea lion (Eumetopias jubatus) (Table 1).

Larvae of reference strains T. spiralis (ISS003), T. nativa (ISS042), T. britovi (ISS002), and T. pseudospiralis (ISS013) were used for comparison. Genomic DNA was extracted from pooled larvae of the tested and reference Trichinella isolates, using Nucleospin Tissue DNA extraction kit (Macherey-Nagel, Germany), according to the manufacturer's instructions.
DNA obtained from each Trichinella isolate was amplified using a multiplex polymerase chain reaction (multiplex PCR) according to Zarlenga et al. (1999) and inter-simple sequence repeat polymerase chain reaction (ISSR-PCR) as described by Fonseca-Salamanca et al. (2006). The reactions were carried out in a Thermo Scientific Thermal Cycler.

Multiplex PCR products were analyzed on $2 \%$ agarose gels and ISSR-PCR products were analyzed on $1.5 \%$ agarose gels stained with GelRed (Biotium) in TAE buffer, at $100 \mathrm{~V}$.

Gels were visualised under UV light and analysed using the Kodak Electrophoresis Documentation and Analysis System KODAK $1 \mathrm{D}^{\mathrm{T}}$. The molecular size of separate bands obtained for tested isolates was calculated and compared to bands obtained for the reference strains.

\section{Results}

Using multiplex PCR, Trichinella was identified in 7 out of the 11 tested isolates (Fig. 1). Using the ISSR PCR for molecular typing, in 10 cases the larvae were identified at the species level. The pattern of bands obtained from tested isolates was compared with the patterns known for reference strains. The species were identified when at least two characteristic bands were present on the gel (Fig. 2). Combining the two PCR methods the Trichinella isolates were defined and confirmed in all delivered samples. T. nativa was identified in the majority of the tested wildlife animals; polar bear, wolverine, arctic foxes, brown bear, sledge dog and northern sea lion. In four animals, mixed infection with two Trichinella species was detected. T. spiralis/T. pseudospiralis were identified in one domestic pig and T. spiralis/T. nativa were found in two arctic foxes and one northern sea lion (Table 1).

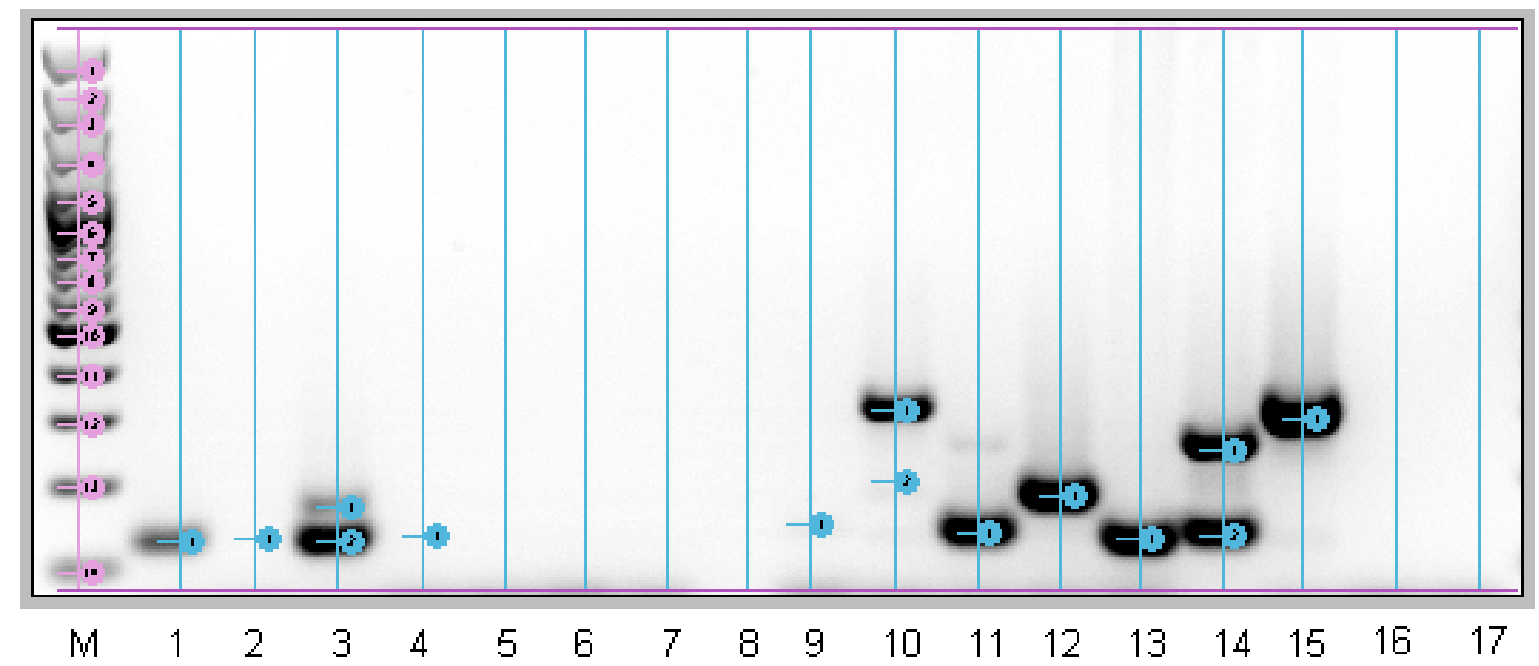

Fig. 1. Analysis of multiplex PCR products: lines 1 - 11 Trichinella isolates obtained from naturally infected wild and domestic animals from Russian Federation; line 12 - T. spiralis reference strain; line 13 - T. nativa reference strain; line 14 - T. britovi reference strain; line 15 - T. pseudospiralis reference strain; lines 16 - 17 negative controls; line $\mathrm{M}$ - molecular size marker (GeneRuler 100 bp Plus ladder, Fermentas). 


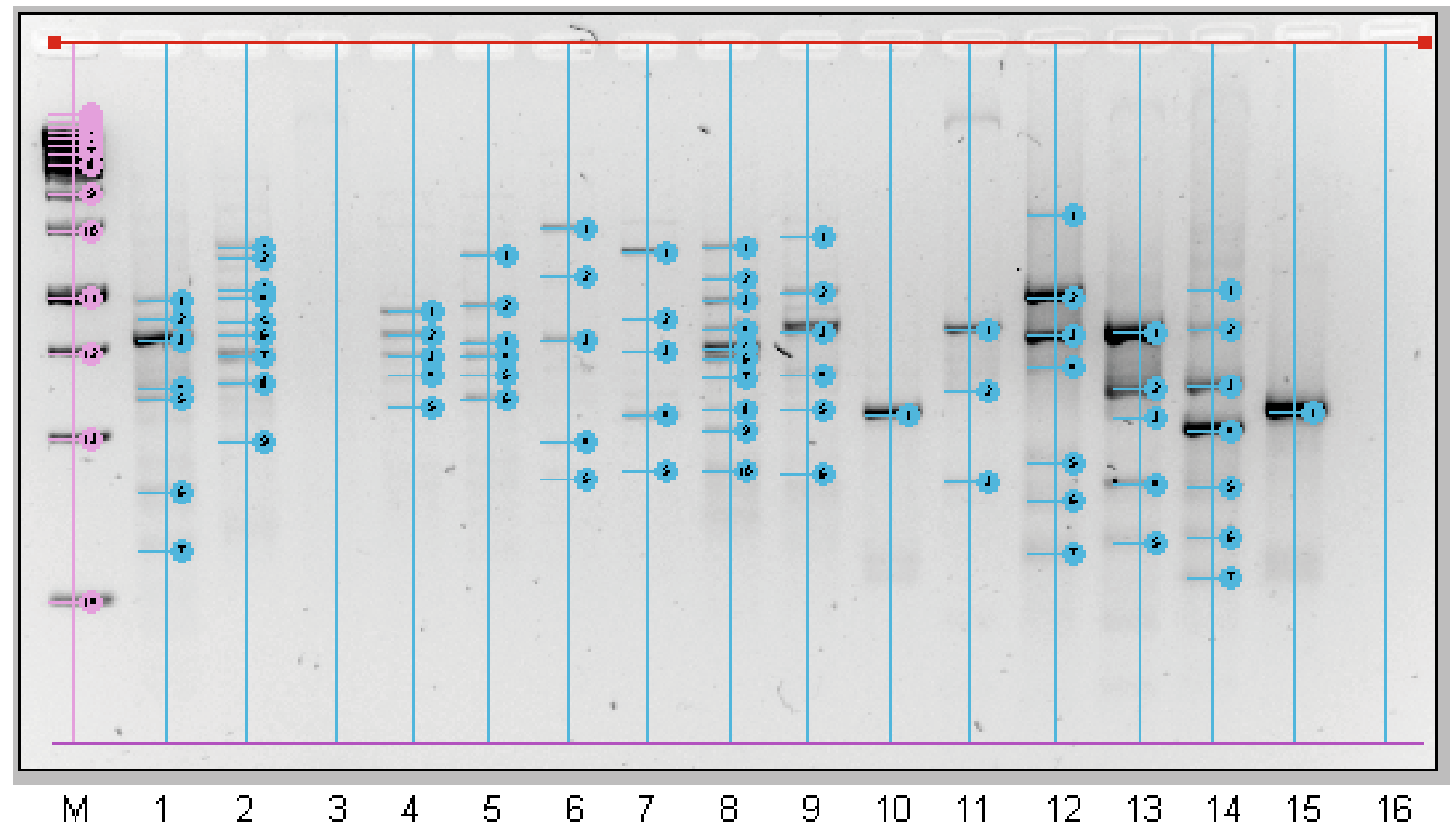

Fig. 2. Analysis of inter-simple sequence repeats PCR products amplified with primer 816 . Lines $1-11$ Trichinella isolates obtained from naturally infected wild and domestic animals from Russian Federation; line 12 - T. spiralis reference strain; line 13 - T. nativa reference strain; line 14 - T. britovi reference strain; line 15 - T. pseudospiralis reference strain; line 16 - negative control; line M - molecular size marker (GeneRuler 1 Kb ladder, Fermentas).

\section{Discussion}

This study reports, for the first time, Trichinella spp. infection in the northern sea lion, also known as Steller sea lion (Eumetopias jubatus). Additionally, using molecular tools, we confirmed that the northern sea lion is a new host for two species of Trichinella; $T$. spiralis and T. nativa.

Northern sea lions are the largest of the Otariidae (eared seals) and are distributed around the rim of the North Pacific Ocean from California to northern Japan. They remain primarily between intertidal zones and continental shelves, but they are also known to enter estuarine environments. They are skilled and opportunistic marine predators, feeding on a wide range of fish and cephalopod species. However, occasionally, northern sea lions have been observed killing and eating northern fur seal pups, ringed seals and sea otter pups (Seal Conservation Society, 2011; Canisius College).

The infection status in this species has not been previously documented. In general, only a few surveys on the occurrence of Trichinella spp. in seals were conducted. Larvae of Trichinella were found very occasionally in circumpolar Arctic species such as the ringed seal (Phoca hispida) and bearded seal (Erignathus barbatus) and in one grey seal only (Halichoerus grypus) found in Baltic sea, a highly Trichinella sp. endemic area, near coastal waters of Finland. Trichinella has not been reported in marine mammals such as California sea lions (Zalophus californianus) or harbor seals (Phoca vitulina) so far (Isomursu and Kunnasranta, 2011; Seymour et al., 2014).
Trichinella isolates used in our study were obtained from animals captured in the northeastern region of Russia, Chukotka Peninsula in the Far Eastern Federal District and Arkhangelsk Oblast in the Northwestern Federal District. The number of samples used in this study for molecular investigation was limited. The material was unique and difficult to obtain due to the animals' species, especially wild animals, and the areas from which it originates.

In this study we utilized two different molecular techniques routinely used in our laboratory for Trichinella larvae identification. The first was a multiplex PCR routinely used with five different PCR primer sets for simultaneous amplification to produce a unique electrophoretic DNA banding pattern for the seven Trichinella species (T1, T2, T3, T4, T5, T6, T7). However for this study, we employed primers sets for the differentiation of only four species of Trichinella existing in the Holarctic region; T. spiralis, T. nativa, T. britovi and T. pseudospiralis (Zarlenga et al., 1999). Unfortunately, using this multiplex PCR identification of larvae was impossible in four cases, probably due to DNA degradation. It was the main reason why we decided to employ another technique, inter-simple sequence repeat polymerase chain reaction (ISSR PCR) for larvae identification. This method also allows the identification of seven Trichinella genotypes. However, the advantages of this technique is that only one primer is needed to amplify repetitive sequences in the genome and less DNA is required as starting material. Since both molecular techniques amplify different regions in the genome of the parasite, combined together, lead to the identification of all delivered Trichinella samples. 
T. nativa was identified in the majority of the tested wild animals. This species was confirmed in a wolverine, three arctic foxes, a polar bear, a brown bear, a sled dog and a northern sea lion. The presence of $T$. nativa in the majority of animals in this region is not surprising since Arctic and subarctic areas are typical geographical areas for the distribution of this species (Pozio, 2000; 2009). According to the results of an epizootological survey presented by Odoyevskaya, T. nativa is widespread among land and marine mammals in the arctic areas of the Russian Federation (Odoyevskaya et al., 2014; 2015).

T. nativa infection was also detected in a natural population of wolves in the Tvier and Smolensk regions of northwest European Russia. The very high prevalence of infection with this species was explained by the human impact on the natural ecosystem, especially, the hunting practices where animal carcasses were left in the forest as a bait (Casulli et al., 2001; Pozio et al., 2001).

In four animals, mixed infection with two Trichinella species was detected. T. spiralis/T. nativa was identified in two arctic foxes and a northern sea lion; and T. spiralis/T. pseudospiralis in a domestic pig. Mixed infections with two species of Trichinella may occur in animals when they have access to food from different sources. The detection of $T$. nativa in arctic foxes and a northern sea lion confirmed the presence of this species in Trichinella-infected animals in this part of Russia.

The presence of $T$. spiralis in arctic animals suggests environmental contamination and can be explained by its cosmopolitan distribution, wide host range and the ability to infect apace the surrounding fauna (Pozio, 2009). T. spiralis is mainly associated with domestic pigs and its infection in marine mammal species may transpire from utilization of coastal or near shore habitats in close proximity to the agricultural areas where run-off from livestock operations occurs (Seymour et al., 2014).

T. pseudospiralis is a cosmopolitan species and is typical for the Palearctic and Nearctic. This species has the ability to infect mammals as well as birds. It has been found to occur naturally in wild carnivores, meat eating birds, marsupials, rodents and swine (Kapel, 2000; Gottstein et al., 2009). In general, wildlife acts as a reservoir and hosts for different pathogens that can be transmitted to domestic animals and/or to humans. On the other hand, contamination of the environment by carcasses or by spread of scraps and offal from animals is important for Trichinella spp. infection in free living animals (Gottstein et al., 2009). Discovery of Trichinella spp. infection in a new host, such as the northern sea lion, which is an opportunistic marine predator, mainly feeding on fish, corroborates with this statement.

Regarding epidemiological studies and improvement of our knowledge about the occurrence and the Trichinella spp. spread in the domestic and sylvatic cycles all isolates should be identified up to the species/genotype level.

However, further extensive epidemiological and molecular studies are required to investigate the local fauna, focusing on carnivore and omnivore mammals, as well as birds living on the Russian territory.

\section{Acknowledgements}

Material for this study was provided to the Witold Stefanski Institute of Parasitology, Polish Academy of Sciences by Professor Sergei O. Movsessyan from Center of Parasitology, A.N. Severtsov Institute of Ecology and Evolution of the Russian Academy of Sciences, Moscow, Russia.

\section{References}

Bukina L.A., Odoyevskaya I.M., ShuǏkInA É.E. (2013) The intensity of immune response to Trichinella nativa antigen in the residents of coastal settlements in the Chukotka district, Chukotka Autonomous Okrug. Med. Parazitol. (Mosk), 3:12 - 15. (In Russian) BukInA L.A. (2014) [Possible sources of Trichinella infection in the indigenous population of Chukotka]. Med. Parazitol. (Mosk.), 3: 17 - 19 (In Russian)

Canisius College: Northern Sea Lion or Steller's Sea Lion. In: Canisius Ambassadors for Conservation. Retrieved from http://www. conservenature.org/learn_about_wildlife/marine_mammals/northern_sea_lion.htm

Casulli, A., La Rosa, G., Amatı, M., Pozio, E. (2001): High prevalence of Trichinella nativa infection in wolf (Canis lupus) populations of Tvier and Smoliensk regions of European Russia. Parasite, 8(2 Suppl): S88 - 89

Fonseca-Salamanca, F., Nogal-Ruiz, J.J., Benito, C., Camacho, M.V., Martinez-Fernandez, A.R. (2006): Molecular characterization of Trichinella genotypes by inter-simple sequence repeat polymerase chain reaction (ISSR-PCR). J. Parasitol., 92: 606 - 610

Gottstein, B., Pozıo, E., Nockler, K. (2009): Epidemiology, Diagnosis, Treatment, and Control of Trichinellosis. Clin. Mic. Rev., 127 - 145 DOI:10.1128/CMR.00026-08

IsOMURSU, M., KunNaSRANTA, M. (2011): Trichinella nativa in Grey Seal Halichoerus grypus: spill-over from a highly endemic terrestrial ecosystem. J. Parasitol., 97(4): 735 - 736 DOI:10.1645/GE2717.1

KAPEL, C.M.O. (2000): Host diversity and biological characteristics of the Trichinella genotypes and their effect on transmission. Vet. Parasitol., 93: 263 - 278

Krivokapich, S.J., Pozio, E., Gatti, G.M., Gonzalez Prous, C.L., Ribicich, M., Marucci, G., La Rosa, G., Confalonieri, V. (2012): Trichinella patagoniensis $\mathrm{n}$. sp. (Nematoda), a new encapsulated species infecting carnivorous mammals in South America. Int. J. Parasitol., 42: 903 - 910 DOI:10.1016/j.ijpara.2012.07.009

Odoevskaya, I.M., SpiRidonov, S.E. (2014): Molecular taxonomic study of Trichinella spp. from mammals of Russian Arctic and subarctic areas. Czech. Polar. Rep., 4: 40 - 46 DOI:10.5817/ CPR2014-1-4

Odoyevskaya, I.M., Uspensky, A.V, Seriodkin, I.V., Bukina, L.A. (2015): The peculiarities of trichinellosis epidemiology in the Arctic territories of the Far Eastern Federal District of Russia. Interenational Commission on Trichinellosis Berlin, Germany $14-18$ 
September 2015. In Abstracts 14th International Conference on Trichinellosis, pp 141

Pozıo, E. (2000): Factors affecting the flow among domestic, synanthropic and sylvatic cycles of Trichinella. Vet. Parasitol., 93: 241 $-262$

Pozio, E., Casulli, A., Bologov, V.V.., Marucci, G., la Rosa, G. (2001): Hunting practices increase the prevalence of Trichinella infection in wolves from European Russia. J. Parasitol., 87: 1498 - 1501 DOI:10.1645/0022-3395(2001)087

Pozio, E., Hoberg, E., La Rosa, G., Zarlenga, D.S. (2009): Molecular taxonomy, phylogeny and biogeography of nematodes belonging to the Trichinella genus. Infect. Genet. Evol., 9: 606 - 616 DOI:10.1016/j.meegid.2009.03.003
Seal Conservation Society (2011): Steller Sea Lion (Eumetopias jubatus). In: IUCN STATUS (2010) - ENDANGERED. Retrieved from http://www.pinnipeds.org/seal-information/species-information-pages/sea-lions-and-fur-seals/steller-sea-lion

Seymour, J., Horstmann-Dehn, L., Rosa, C., Lopez, J.A. (2014): Occurrence and genotypic analysis of Trichinella species in Alaska marine-associated mammals of the Bering and Chukchi seas. Vet. Parasitol., 200: 153 - 164 doi.org/10.1016/j.vetpar.2013.11.015 Zarlenga, D.S., Chute, M.B., Martin, A., Kapel, C.M.O. (1999): A multiplex PCR for unequivocal differentiation of all encapsulated and non-encapsulated genotypes of Trichinella. Int. J. Parasitol., 29: $1859-1867$ 